\title{
BOWTIE ANALYSIS AS A TOOL FOR VISUALIZATION OF THE RISK SCENARIO
}

\section{Katarina Petrlova}

Silesian University, Mathematical Institute in Opava, Opava, Czech Republic

\section{Maria Polorecka}

University of Zilina, Faculty of Security Engineering, Zilina, Slovak Republic

CMESTE

JEL Category: H12, D81

\begin{abstract}
The article aims to apply the bowtie analysis to the visualization of a development of a specific scenario of the combined risk. Its authors build on their previous work, where they started with the typology, interactions and the definition of the combined risk and determined the probability of formation of the combined risk. The aim of the present article is the visualization of the scenario where a natural event triggers the release of dangerous chemicals by the application of the bowtie analysis. It was achieved by using two well-known methods of the risk analysis - the fault tree analysis and event tree analysis. Through the methods used, the authors obtained the basic model trees for the causes and consequences. The next step, as an addition to the used method, was to establish particular barriers that could be used to decrease the probability of a top event or to decrease the consequences. This information is the best basis for further analyses of the phenomenon of the combined risk (when a natural disaster triggers the release of dangerous goods).
\end{abstract}

Keywords: risk, simulation, analysis, accidents, decision-making

\section{INTRODUCTION}

Nowadays, the issue of combined risks is increasingly dealt with by the concerned institutions and organizations, especially by the Joint Research Centre (JRC), which is part of the European Union, as well as the Organization for Economic Co-operation and Development (OECD).

There are several types of combined risks, but our work focuses on the natural hazards triggering a technological disaster or calamity. The reason for

Address of the corresponding author: Katarína Petrlová

拝=" Katarina.Petrlova@math.slu.cz our choice is the fact that this type of combined risks is the most common type of risks not only in the Czech Republic and Slovakia but also in most countries, as evidenced by many situations around the world. These types of combined risks are also called NATECH accidents - that is chemical accidents triggered by natural events (Krausmann, E., Cozzani, V., Salzano, E., Renni, E., 2011).

\section{STARTING POINTS FOR COMBINED RISK RESEARCH}

As a result of our previous work (Simonova, M., Jelsovska, K., 2011): defining the term "combined risk" is slightly more complex, since it is a combination of at least two individual risks, and 
this combination is not delineated. Different kinds and types of individual risks may enter into mutual interactions, which have different dependencies and mechanisms, and they are conditioned by many factors as well as the origin of individual risk is.

Therefore, prior to the definition of the combined risk, the determination of the basic environment is necessary, i.e., the risk conditions (origin of the risk), the time course of a risk and the relation of individual risks involved in this combination and their effect on a subject.

In order to be able to define a combined risk, it is, however, necessary to consider the risk in a wider aspect. For the purposes of this article, it will be sufficient to define risks in terms of the environment in which they arise. This environment determines the nature of the risk and its possible participation in the combined risk.

The origin of a risk is a basic characteristic of the risk. According to many authors and literary sources, the origin of a risk may come from many environments. There is a general and basic classification of risks - a natural risk on one hand and an anthropogenic on the other one.

When defining the combined risk, we consider it essential that in a mutual combination at least two types of individual risks must be represented. Where represented by only one type, we do not consider this as the combined risk (therefore, a flood and its subsequent landslides cannot be considered as the combined risk, for example.)

According to its environments, the definition of the combined risk is as follows (Simonova, M., Polorecky, D., Dobes, P., 2010): the combined risk is characterized by an interactive link between risks origination from at least two different environments. The environment is seen as something which is not closed, and which is characterized by communication (flow of energy and information) with other environments. The interactive connection is a relation that can be characterized as a mutual synergy or mutual triggering of individual risks. It is irrelevant whether it is a relation of probabilities or a relation of the consequences of primary individual risks involved in the combination.

From our previous paper the typology of combined risks follows - the natural and technological one (Simonova, M., Jelsovska, K., 2011):

- Initiation of a technological accident by a natural disaster.

- Initiation of a natural disaster by a technological accident.

- Domino effect - a technological accident triggers another technological accident.

- Concatenation of natural emergencies.

- The synergy of technological accidents and environmental conditions.

- The synergy of natural disasters and technological conditions.

- Accumulation - a parallel action of natural and technological events.

If follows conclusively that in the study of risks and crises resulting from the risks attention should be paid not only to the individual primary types of risks but also their combinations; in our case, particularly the combination of natural and technological risks.

In the part about the typology of the combined risks, we indicated seven possible combinations. This work, nonetheless, is aimed at one of these namely the initiation of a technological accident by a natural disaster.

The process of interaction is described in Fig. 1. This case is common in practice when by the outbreak of natural disasters technological equipment is subsequently threatened and disturbed, which leads to an occurrence of accidents. There are many cases in history, for example, releases of hazardous substances from factories during the floods, threats of technology due to natural fires, damages to critical infrastructure assets due to storms, possibly to snow disasters, or landslides.

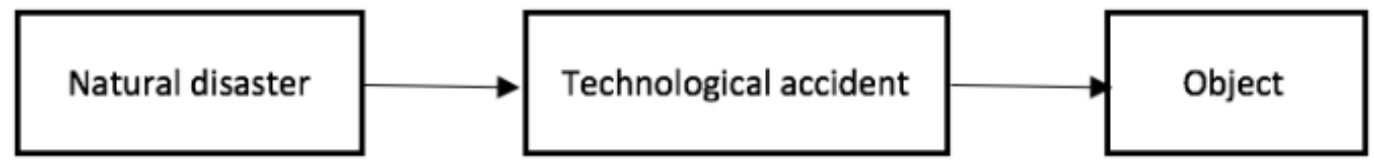

Fig. 1 Initiation of a Technological Accident by a Natural Disaster

Source: (Simonova, M., Jelsovska, K., 2011) 
It is well known that natural disasters can trigger secondary disasters such as toxic air releases, spills of hazardous materials and fires or explosions. These secondary technological disasters triggered by natural disaster events are termed "NATECH" (natural hazards triggering technological disasters) (Cruz, 2005).

The aim of this paper is to find an appropriate method to determine the probability of the NATECH which would also be applied not to only one specific example and/or case, and that it be also straightforward and accurate.

In our last work (Polorecka, M., Byrtusova, A., Jelsovska, K., 2015) we described using the Bayesian network for the probability of the NATECH. We outlined the probability theory, conditional probability, Bayesian networks and, at last, the methodology itself. We chose a case where a flood that might occur could possibly affect the two companies in the immediate vicinity of a watercourse and a nearby power plant (Polorecka, M., Byrtusova, A., Jelsovska, K., 2015).In this article, we describe the bowtie analysis as another method applicable to the probability of the NATECH. Consequently, first, a brief description of the theory will be done.

\section{BOWTIE ANALYSIS}

The catastrophic incident on the Piper Alpha platform in 1988 awoke the oil and gas industry. After the report that there was far too little understanding of hazards and their accompanying risks that are parts of operations, the urge rose to gain more insight in the causality of seemingly independent events and conditions and to develop a systematic way of assuring control over these hazards.

In the early nineties, the Shell Group adopted the bowtie method as the company's standard for analyzing and managing risks. Following Shell, the bowtie method rapidly gained support throughout the industry, as bowtie diagrams appeared to be a suitable visual tool to keep an overview of risk management practices, rather than replacing any of the commonly used systems (The Bowtie Method, 2018).

As a result, the bowtie analysis is a risk analysis technique that can be used to analyze and demonstrate causal relationship in high-risk scenarios. The bowtie analysis, similarly to the cause and effect analysis, describes and analyses the ways from the causes of a risk to its consequences. In principle, it is a combination of the fault tree analysis (FTA) for analyzing the causes of events and the event tree analysis (ETA) for analyzing the consequences of the events (Korecky, M., Trkovsky, V., 2011). The aim of this method is a representation of the mechanism of the origin and consequences of risks. It is useful for discussions about the causes and consequences of risks and possibilities for treatment risks both in the preventive and reactive sense. It is also possible to determine the consequences of the stated risks by means of this method.

For present purposes, it is necessary to explain some of the basic terms connected with the bowtie analysis. The elements of bowtie analysis are (Hamzah, 2012):

- Hazard - A potential source to endanger citizens, property, the environment, and company reputation.

- Top Event - An incident that occurs when a hazard is realized.

- Threats - What could cause the top event to occur?

- Consequences - What could happen if the top event occurs?

- Barrier - What directly prevents or reduces the probability of a threat?

- Recovery Measure - what prevents, minimizes, or helps recovery from the consequence?

The relationship of the elements in a bowtie analysis is described in Fig. 2.

The advantage of the method lies in its clearness and appropriate use for risk analysis. It is also useful to discuss and develop strategies for risk treatment. At the same time, its disadvantage lies in certain simplicity consisting in a direct relation of each cause to a risk, which can lead to an excessive simplification of a complex situation. If desired, effects that are more complex can be plotted in the form of a simple tree structure. 


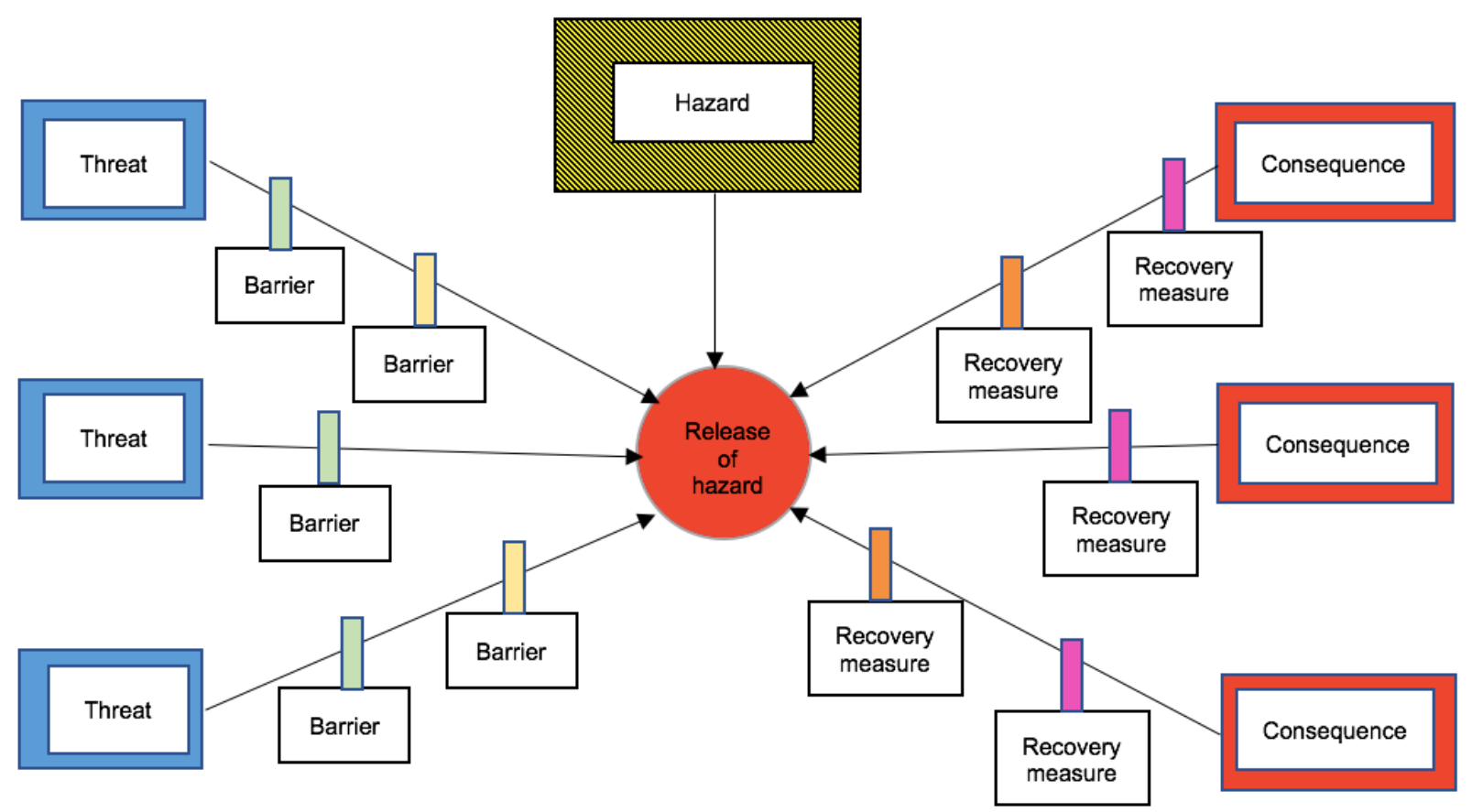

Fig. 2 Relationship of the Elements in a Bowtie (authors, 2018)

\section{METHODOLOGY}

The starting point of the bowtie analysis is a hazard. A hazard is something in, around or part of the organization which has the potential to cause damage, i.e., an explosive material in the facility. Once the hazard is pointed at, the next step is to define the top event. There is no damage or negative impact yet, but it is imminent. This means that the top event is chosen just before the events start causing the actual damage, i.e., an explosive material is ignited. The next step is a list of threats. The threats are whatever will cause a top event. The list of threats is followed by determining the consequences. The consequences are the result of a top event. There can be more than one consequence for every top event. At this stage, a clear understanding of the risk and the unwanted scenarios are done. Using barriers is the next step. In the bowtie analysis, the barriers appear on both sides of the top event. The barriers interrupt the scenario so that the threats do not result in a top event or do not escalate the consequences.

\section{EXAMPLE}

In this article the following specified NATECH scenario was chosen (Dobes, P., Dlabka, J., Jelsovska, K., Polorecka, M., Baudisova, B., Danihelka, P., 2015): heavy rainfalls AND/OR melting snow lead to landslides AND/OR floods and this situation causes a major chemical accident for a visualization of development of the scenario.

In the first step of the analysis, an object must be established. Because many NATECH events could be classified as crisis situations or emergencies, we count with the SEVESO installation where dangerous chemicals are stored or handled.

In the second step, the hazard is chosen. In this case, the hazard is a major release of chemicals into the environmental compartments (water, soil, air), with the goal to threaten environmental safety in the area. Therefore, the top event for this scenario is the flooding of a SEVESO installation.

The FTA was used to create the left side of the bowtie - for determining the threats, see Fig. 3. On the right side of the bowtie, there are the consequences determined by ETA. See Fig. 4. 


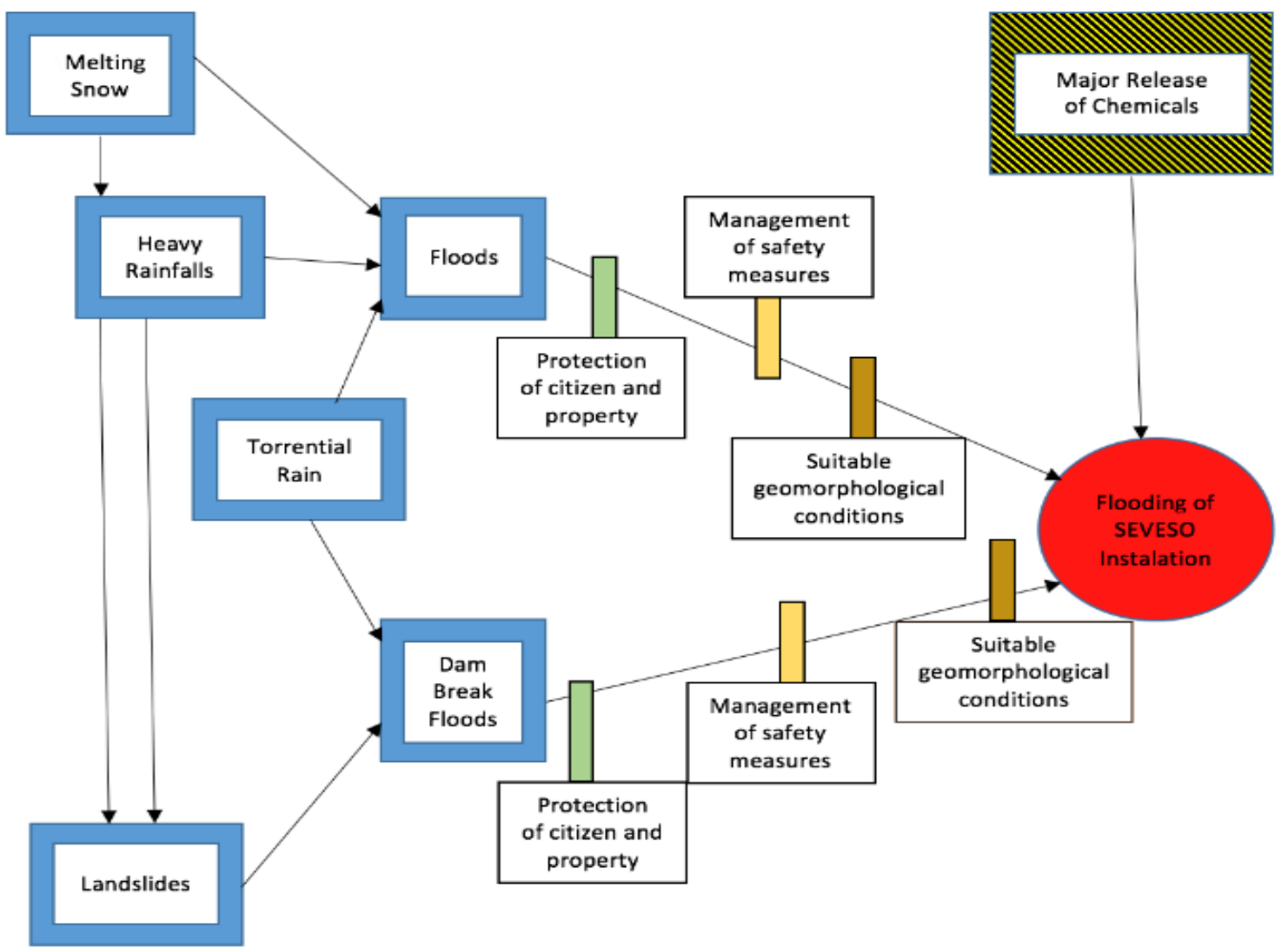

Fig. 3 Threats Determined by the Fault Tree Analysis (authors, 2018)

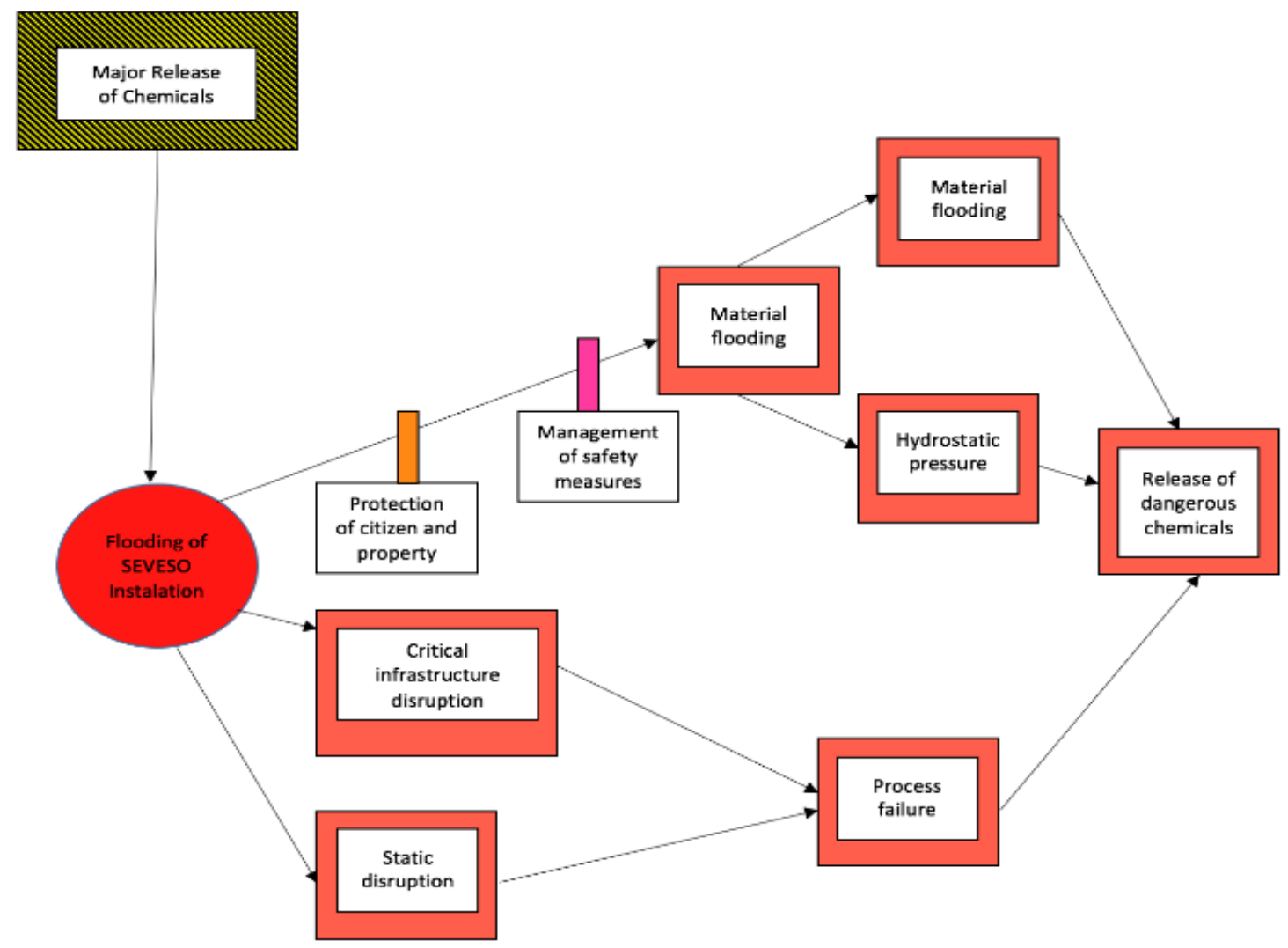

Fig. 4 Consequences Determined by the Event Three Analysis (authors, 2018) 


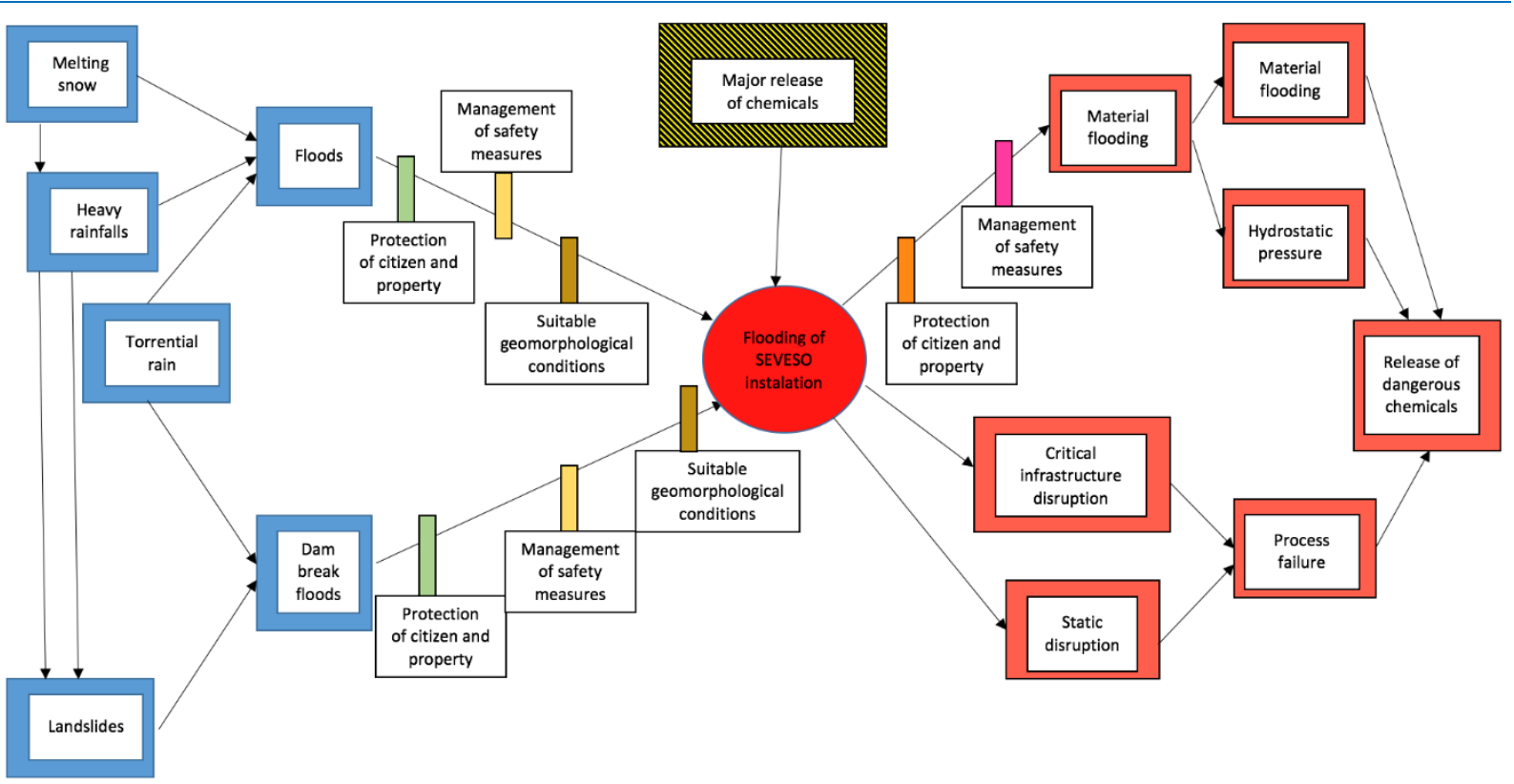

Fig. 5 Bowtie Analysis (authors, 2018)

The aim of this article is presented in Fig. 5.

\section{CONCLUSIONS}

The aim of the present article is a visualization of the scenario where a natural event triggers the release of dangerous chemicals by application of the bowtie analysis. It was achieved by using two well-known methods of risk analysis - the fault tree analysis and event tree analysis. This model can be used as a tool for decision-making of emergency managers before and during a crisis triggered by a top event. The model may also be supplemented by a preventive acting barrier on the left-hand side and reactive control actions to prevent or mitigate the consequences on the righthand side. Those, however, were not the objective of the article. It is also possible to add the probability of individual events by using the Bayesian network. But it is necessary to reckon with the fact that there is not always enough quantitative information from monitoring of historical emergencies. The expert belief and expectation, as well as classical frequentist inputs, are needed. In addition, there could be several dependent or independent variables necessary to consider and, in general, - every emergency situation has always a little different run. Determining the probability of this scenario will be the subject of our next research.

\section{WORKS CITED}

Cruz, A. M. (2005). Natech Disasters: A review of Practicies, Leassons Learned and Future Research Needs. 5th Annual IIASA-DPRI Forum.

Dobes, P., Dlabka, J., Jelsovska, K., Polorecka, M., Baudisova, B., Danihelka, P. (2015). Using of Bayesian Networks to Estimate the Probability of "NATECH" Scenario Occurrence. Geophysical REsearch Abstracts Vol. 17. Vienna: EGU General Assembly.

Hamzah, Z. S. (2012). Use Bow Tie Tool for Easy Hazard Identification. 14th Asia Pacific Confederation of Chemical Engineering Congress.

Korecky, M., Trkovsky, V. (2011). Management rizik projektu se zamerenim na projekty v prumyslovych podnicich. Praha: Grada Publishing, a. s.

Krausmann, E., Cozzani, V., Salzano, E., Renni, E. (2011). Industrial Accidents triggered by natural hazards: an emerging risk issue. Nat. Hazards Earth Syst. Sci., pp. 921-929. 
Polorecka, M., Byrtusova, A., Jelsovska, K. (2015, 3 23-27). Determine the Probability of Formation of Combined Risk. CER Comparative European Research 2015, Internal Scientific Conference for Ph.D. students of EU countries.

Simonova, M., Jelsovska, K. (2011, Nov 24-25). Zakladne vychodiska pre vyskum v oblasti kombinovanych rizík. Medzinarodni konference mladych vedeckych pracovniku a doktorandu. Ostrava: Fakulta bezpečnostního inženýrství, Technická univerzita Ostrava.

Simonova, M., Polorecky, D., Dobes, P. (2010). Navrh definicie terminu "kombinovane rizika". Delta: vedecko-odborny casopis Katedry protipoziarnej ochrany DF TU vo Zvolene, pp. 6-10.

The Bowtie Method. (2018). Retrieved from CGE Risk Management Solutions: http://www.cgerisk.com/knowledge-base/risk-assessment/thebowtiemethod

Received for publication: $\quad 01.04 .2018$

Revision received: $\quad 16.05 .2018$

Accepted for publication: $\quad$ 07.06.2018

\section{How to cite this article?}

Style - APA Sixth Edition:

Petrlova, K., \& Polorecka, M. (2018, July 15). Bowtie Analysis as a Tool for Visualization of the Risk Scenario. (Z. Cekerevac, Ed.) MEST Journal, 6(2), 99-103. doi:10.12709/mest.06.06.02.12

Style - Chicago Sixteenth Edition:

Petrlova, Katarina, and Maria Polorecka. 2018. "Bowtie Analysis as a Tool for Visualization of the Risk Scenario." Edited by Zoran Cekerevac. MEST Journal (MESTE) 6 (2): 99-103. doi:10.12709/mest.06.06.02.12.

Style - GOST Name Sort:

Petrlova Katarina and Polorecka Maria Bowtie Analysis as a Tool for Visualization of the Risk Scenario [Journal] // MEST Journal / ed. Cekerevac Zoran. - Toronto : MESTE, July 15, 2018. - 2 : Vol. 6. - pp. 99-103.

Style - Harvard Anglia:

Petrlova, K. \& Polorecka, M., 2018. Bowtie Analysis as a Tool for Visualization of the Risk Scenario. MEST Journal, 15 July, 6(2), pp. 99-103.

Style - ISO 690 Numerical Reference:

Bowtie Analysis as a Tool for Visualization of the Risk Scenario. Petrlova, Katarina and Polorecka, Maria. [ed.] Zoran Cekerevac. 2, Toronto : MESTE, July 15, 2018, MEST Journal, Vol. 6, pp. 99-103. 